Article

\title{
Bearings Downsizing by Strength Enhancement and Service Life Extension
}

\author{
Auezhan Amanov *, Shirmendagva Darisuren and Young-Sik Pyun \\ Department of Mechanical Engineering, Sun Moon University, Asan 31460, Korea; \\ shirmee9999@naver.com (S.D.); pyoun@sunmoon.ac.kr (Y.-S.P.) \\ * Correspondence: avaz2662@sunmoon.ac.kr; Tel.: +82-41-530-2892; Fax: +82-41-530-8018
}

Received: 14 July 2018; Accepted: 7 September 2018; Published: 8 September 2018

\begin{abstract}
Slim bearings are used widely in aircrafts, robots, wind turbines, and industrial machineries, where their size and weight are very important for the performance of a system. The common materials of slim bearings for robots and industrial machineries are based on SAE52110 bearing steel, and special heat treatment and a super polishing process are used and adapted to improve the rolling contact fatigue (RCF) strength of bearings. The improvement in RCF strength, depending on contact stress, surface hardness, and the friction behavior before and after ultrasonic nanocrystalline surface modification (UNSM) treatment was validated. Simple analysis shows that these improvements can reduce the size and weight of slim bearings down to about $3.40-21.25 \%$ and $14.3-26.05 \%$, respectively. Hence, this UNSM technology is an opportunity to implement cost-saving and energy consuming super-polishing, a heat treatment process, and to reduce the size and weight of slim bearings.
\end{abstract}

Keywords: bearing; rolling contact fatigue strength; ultrasonic nanocrystalline surface modification (UNSM); hardness; roughness; super-polishing

\section{Introduction}

Todays' requirements for extended service life and the increased downsizing of bearings are associated with reliability and the manufacturing cost of equipment. Slim, thrust ball, and spherical roller bearings are widely used in aircrafts, robots, wind turbines, and industrial machineries, where their size and weight are very important for the performance of a system. Rolling element bearings (REBs) are commonly used in tribo-machineries such as wind turbines, transmission, engines, etc. [1]. The size and weight of the inner and outer rings of slim bearings should be reduced as much as possible until they satisfy rolling contact fatigue (RCF) strength. The process of pitting failure involves the initiation of micro-cracks within the stressed volume via a damage accumulation process, subsequently followed by their growth, which eventually leads to the generation of surface pits and the ultimate failure of the component [2]. In this regard, common materials of the rings for aircraft jet engine bearings are special alloy steels, such as $\mathrm{M}$ series, and special heat treatment for refined micro grain, a high hardness of more than 63 HRC (Rockwell), compressive residual stress, and super finishing are usual processes for a very high cycle rolling strength of the rings. The general trend of an increase in fatigue life with increasing hardness has been observed earlier [3]. There are ceaseless efforts to develop new materials, a heat treatment process, and a super-polishing process to improve high cycle rolling contact fatigue strength, however their cost and energy are very high and even these technologies are controlled as confidential knowhow of suppliers and customers [4]. Materials in REBs are stressed during cyclic loading, resulting in the formation of irreversible subsurface microstructural alterations such as dark etching region (DER) and white etching bands (WEBs), slim bearings for robots, and a special reduction system of industrial machinery could not adapt such special alloy steel and processes due to high cost and confidential know-how. Consequently, general bearing steel such as SAE52100 is used for 
rings and rollers. DER has been reported to typically form under moderate to high contact stresses in the area of maximum shear stress after a high number of rolling cycles (5-100 $\times 10^{6}$ cycles). DER has also typically been found at a depth of approximately $0.10-0.65 \mathrm{~mm}$ below the contact surface [5]. DER typically spans between 0.5 and $2 \mathrm{~mm}$ in the depth direction, however it increases with running time and contact pressure.

Bearing life is influenced by the material microstructure, which is inherently inhomogeneous and, therefore, the fatigue life of an apparently identical batch of bearings operating under identical load, speed, lubrication, and environmental conditions will show a significant degree of scatter. Even a special heat treatment and polishing process have been developed for bearing materials, however their size and weight cannot be reduced due to the limit of RCF strength [6]. For example, Pramanic et al. have studied the fatigue life of machined components [7]. The super-polishing process reduced the surface roughness however, in turn, it removed the surface layers containing compressive residual stress, which tends to increase the fatigue strength of the polished components. Also, the super-polishing process may induce a tensile residual stress due to temperature rise. Moreover, the effects of bainitic-martensitic heat treatment on the microstructure and fatigue life of a bearing steel (SAE52100) have been investigated earlier [8]. It was found that no change in hardness was found, however the fatigue strength was enhanced by the shortened heat treatment process due to the homogenous dispersion of a small amount of austenite. The fatigue life of a bearing steel (SAE52100) by dynamic strain ageing has been investigated in a previous study [9]. It was reported that the dynamic strain ageing treatment introduced a more stable dislocation structure by increasing the mobile dislocation density and locking of these dislocations by diffusing carbon atoms and subsequently forming carbides. In addition to heat treatment, Kerscher and Lang have increased the fatigue life of a bearing steel (SAE52100) by deep cryogenic treatment [10]. Interestingly, the fatigue life increased only after some of the sequences. Hence, both the polishing and heat/cryogenic treatments sometimes may limit the fatigue life of bearings even though the processes increase the surface hardness, reducing the surface roughness, etc. In this regard, a surface modification technology, ultrasonic nanocrystal surface modification (UNSM), is a metal improvement technology which increases the mechanical properties and performance of materials [11]. The purpose of this study is to demonstrate a reduction in the size and weight of bearings for robots or special systems of industrial machineries by adapting a UNSM technology for the rings and rollers in order to reduce energy consumption and material cost.

\section{Validation of UNSM Technology}

The UNSM technology strikes the surface of a workpiece up to 20,000 times per second with a tungsten carbide (WC) and/or a silicon nitride $\left(\mathrm{Si}_{3} \mathrm{~N}_{4}\right)$ ball with a diameter range from 1.0 to $6.0 \mathrm{~mm}$ at a frequency of 20,27, or $40 \mathrm{kHz}$ that modifies the coarse grains into nano-sized grains until a certain depth from the top surface. The UNSM device includes an ultrasonic transducer, a horn, and an impacting tip, which comes into contact with the surface of a workpiece. The horn amplifies the high frequency ultrasonic vibrations that are generated by the transducer. Thus, the ball (tip) delivers static and dynamic loads to the workpiece. The most important advantage of the UNSM technology over other mechanical surface modification technologies is that the controllable static and dynamic loads provide a uniform and homogenous treatment. The main idea of UNSM technology is to introduce a high pressure of up to $30 \mathrm{GPa}$ to a workpiece surface with high frequency strikes of more than 1 million times per minute and up to $100 \mathrm{~K}$ strikes per $\mathrm{mm}^{2}$, utilizing an ultrasonic energy and a resonance amplitude. These high dense and intense cycles pressure induces a high cycle of severe plastic deformation (SPD) up to a certain depth and high cycle of elastic deformation beneath this depth. The changes in mechanical properties and performance by UNSM treatment of a bearing alloy steel have been reported earlier [12]. In order to validate a possible reduction in the size and weight of slim bearings by adapting a UNSM technology, the increase in RCF strength needs to be examined using the experimental test specimens made of SAE52100 first, and a typical standard bearing can be 
selected to justify the effects in the same way on real standard bearings. The specimens and bearings were treated by UNSM technology under the parameters that are listed in Table 1 . The reduction in the friction coefficient by reducing surface roughness and the formation of dimples via UNSM technology showed the possibility of eliminating or replacing a super-polishing process. Finally, the increased dynamic load rating of a typical slim bearings after UNSM technology will be derived based on the ISO standard of the dynamic load rating, and a possible reduction in size and weight of slim bearings will be analyzed and proposed.

Table 1. UNSM treatment parameters.

\begin{tabular}{ccccccc}
\hline $\begin{array}{c}\text { Frequency } \\
\mathbf{k H z}\end{array}$ & $\begin{array}{c}\text { Amplitude } \\
\mathbf{\mu m}\end{array}$ & $\begin{array}{c}\text { Horn Speed } \\
\mathbf{m m} / \mathbf{m i n}\end{array}$ & $\begin{array}{c}\text { Feed-Rate } \\
\mathbf{m m} / \mathbf{r e v}\end{array}$ & $\begin{array}{c}\text { Rotating } \\
\text { Speed rpm }\end{array}$ & $\begin{array}{c}\text { Load } \\
\mathbf{N}\end{array}$ & $\begin{array}{c}\text { Ball Diameter } \\
\mathbf{m m}\end{array}$ \\
\hline 20 & 30 & 3000 & 0.07 & 115 & 60 & 2.38 \\
\hline
\end{tabular}

\subsection{RCF Strength of Ring Specimen by UNSM Technology}

Six-ball RCF test specimens with dimensions of $25 \mathrm{~mm}$ in diameter and $4 \mathrm{~mm}$ in thickness were used. Balls made of SAE52100 bearing steel with a diameter of $9.525 \mathrm{~mm}$ were used as rolling parts between the raceways. Six-ball RCF tests were conducted under elasto-hydrodynamic lubricating conditions at various contact stress levels, as shown in Table 2. When flaking occurred on the surface of the specimens, the vibration sensor detected it and the test was halted automatically. A comparison in cycles to flaking at various stress levels of the untreated and UNSM-treated specimens is shown in Figure 1. Thus, the compressive residual stress was induced from -1227 to $-1343 \mathrm{MPa}$, with an increasing static load from 100 to $110 \mathrm{~N}$, however it decreased from -1343 to $-1091 \mathrm{MPa}$ with an increasing static load of 110 to $120 \mathrm{~N}$, as shown in Table 3. The compressive residual stress of the untreated may be induced by grinding and polishing processes during machining, and at a depth of about $40-80 \mu \mathrm{m}$, the compressive residual stress was eliminated. This indistinct phenomenon may be attributed to the microstructure modification that can be explained in terms of disordering grain dislocations and grain size refinement.

Table 2. RCF test conditions.

\begin{tabular}{ccc}
\hline Hertzian Contact Stress MPa & Rotating Speed rpm & Lubricant \\
\hline 4250 & & \\
4750 & 1000 & Shell Tellus 37 \\
5000 & & \\
5300 & & \\
5800 & & \\
\hline
\end{tabular}

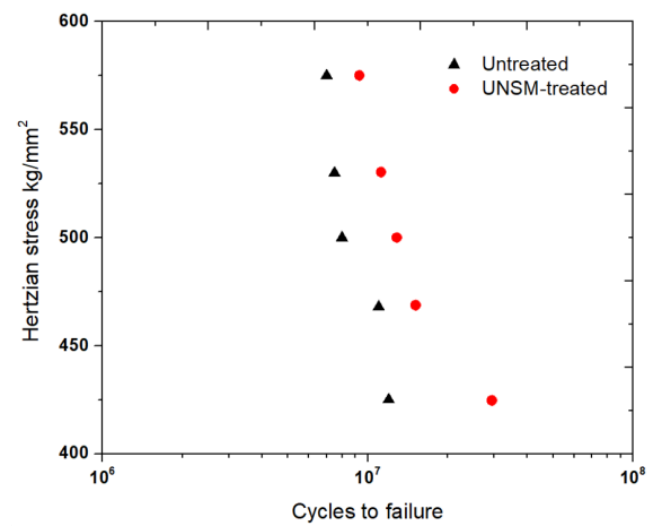

Figure 1. Comparison in S-N (stress-number of cycles) data of the untreated and UNSM-treated specimens at various contact stress levels. 
Table 3. The mechanical properties of the untreated and UNSM-treated specimens.

\begin{tabular}{cccc}
\hline $\begin{array}{c}\text { Static Load of the } \\
\text { UNSM Treatment }\end{array}$ & $\begin{array}{c}\text { Surface Hardness } \\
\text { HV }\end{array}$ & $\begin{array}{c}\text { Surface Roughness }\left(\mathbf{R}_{\mathbf{a}}\right) \\
\boldsymbol{\mu m}\end{array}$ & Residual Stress MPa \\
\hline Untreated & 720 & 0.344 & $\begin{array}{c}-200 \text { (top surface) } \\
200 \text { at a depth of } 160 \mu \mathrm{m}\end{array}$ \\
\hline UNSM-100 & 850 & 0.110 & -1227 \\
\hline UNSM-110 & 864 & 0.105 & -1343 \\
\hline UNSM-120 & 855 & 0.115 & -1091 \\
\hline
\end{tabular}

Figure 2 compares the micro-hardness of the untreated and UNSM-110-treated specimens, which was measured using a micro-Vickers hardness tester (MVK E3, Mitutoyo, Takatsui, Japan) at a load of $300 \mathrm{gf}$ for a dwell time of $10 \mathrm{~s}$. The top surface hardness of the specimen increased to up to $864 \mathrm{HV}$ and then gradually decreased up to $720 \mathrm{HV}$, which is the hardness value of the untreated specimen. The hardness value of the UNSM-110 increased by about $20 \%$ compared to that of the untreated specimen. The increase in the hardness of the UNSM-110-treated specimen in comparison with the untreated one can be attributed to the grain size refinement by the Hall-Petch relationship, where the grain size plays an important role, and can also be attributed to work hardening effects [13].

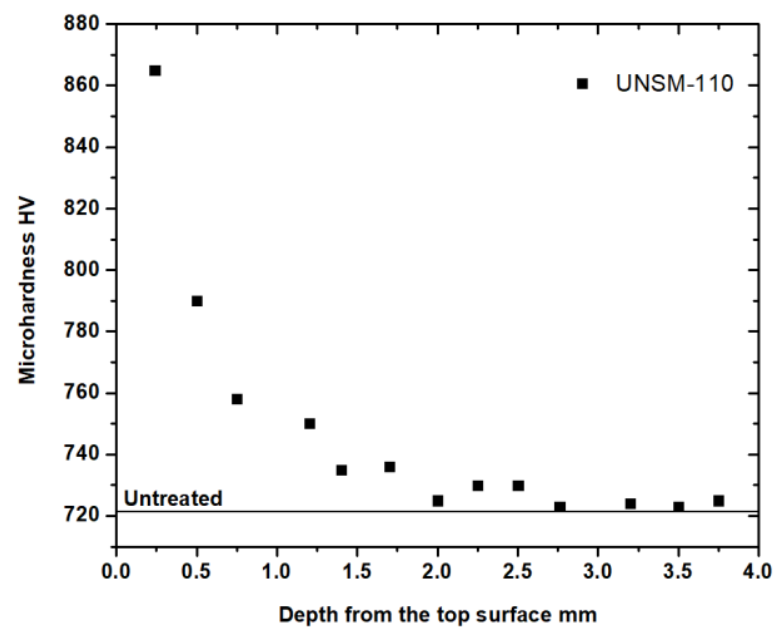

Figure 2. Variation of the micro-Vickers hardness value of the UNSM-110 specimens as a function of the depth from the top surface.

The residual stress results of the untreated and UNSM-110-treated specimens are shown in Figure 3. It shows that the compressive residual stress value from the top surface to the center of the specimen gradually decreased and saturated the residual value in the case of the UNSM-treated specimen, however it rapidly decreased in the untreated specimen. It is interesting to note that the compressive residual stress was not linearly reduced with the increasing impact load of the UNSM technology. The induced compressive residual stress by the UNSM technology can be explained due to the grain size refinement through SPD and stress relieving [14], and it is the major factor in increasing the fatigue strength and crack growth rate of bearings $[15,16]$. Also, it has been reported earlier that the UNSM technology is able to transfer a tensile residual stress into a compressive residual stress [17]. In addition, the degree of the residual stress depends on the UNSM parameters, however there is a need to confirm the values and distribution with respect to depth. However, there is a need to confirm their values and distribution through the depth induced compressive residual stress which was -1227 to $-1343 \mathrm{MPa}$ with an increasing static load from 100 to $110 \mathrm{~N}$, respectively, however it decreased from -1343 to $-1091 \mathrm{MPa}$ with an increasing static load of 110 to $120 \mathrm{~N}$, respectively, as shown in Table 3 . This indistinct phenomenon may be attributed to the microstructure modification that can be explained 
in terms of disordering grain dislocations, dislocation formation and grain growth. However, it is worth mentioning here that there is a limitation on grain size refinement by SPD methods, where a refined grain size that is less than $10 \mathrm{~nm}$ may deteriorate the mechanical and other properties of materials [18].

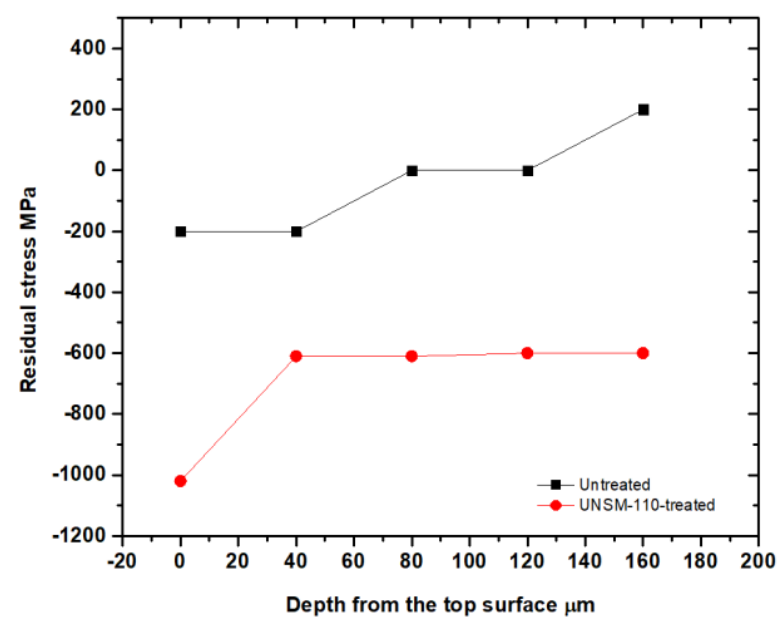

Figure 3. Variation of the compressive residual stress value of the untreated and UNSM-110-treated specimens as a function of the depth from the top surface.

\subsection{Validation in Thrust Ball Bearing Fatigue Life Test}

In order to justify the effect of UNSM technology in real bearings, a thrust ball bearing was selected and a comparison test was performed at a Hertzian stress of 5 GPa with 1500 rpm under oil lubricated conditions. At least three samples were used for each fatigue result due to data scattering. Average cycles to failure of the untreated new bearing was found to be $1.81 \times 10^{6}$ cycles and the UNSM-treated bearing was run-out after $3.06 \times 10^{6}$ cycles, as shown in Table 4 .

Table 4. RCF test results.

\begin{tabular}{ccc}
\hline New Bearing & Used Bearing & Used Bearing Treated by UNSM \\
\hline $1.81 \times 10^{6}$ cycles & $4 \times 10^{5}$ cycles & $3 \times 10^{6}$ cycles \\
\hline
\end{tabular}

\subsection{RCF Strength of Rollers by UNSM Technology}

The RCF test specimens made of SAE52100 with a diameter of $15 \mathrm{~mm}$ and a length of $300 \mathrm{~mm}$ were used. The result of the effect of repeating load being applied to the specimen on the RCF life showed that the fatigue life was shortest at $122 \mathrm{~N}$ and it increased more than 3 times from $13 \times 10^{6}$ to $41 \times 10^{6}$ cycles after UNSM treatment, even under the same load of $1200 \mathrm{~N}$ and with a rotation speed of $8000 \mathrm{rpm}$. SPD that was caused by repeated maximum shear stress during RCF test increased dislocation density and the stress-induced diffusion of $C$ atoms, which are supersaturated in surrounding martensite which occurs along the high diffusion paths, which results in the formation of deformation bands along maximum shear.

\subsection{Validation in Spherical Roller Bearing Fatigue Life Test}

In order to justify the effect of UNSM technology in real bearings, a spherical roller bearing (designation FAG24020) was selected for a comparison test that was performed under the test conditions that are listed in Table 5. Cycles to failure under the Herzian stress of 2.9 GPa of the untreated and UNSM-treated bearings was $6.5 \times 10^{5}$ and $1 \times 10^{6}$ run out, as listed in Table 6 . 
Table 5. Spherical roller bearing fatigue life test conditions.

\begin{tabular}{cccc}
\hline Time, $\mathbf{h}$ & Load, $\mathbf{k N}$ & Rotating Speed, rpm & Lubrication Type \\
\hline 83.24 & 255 & 200 & ISO VG 46 \\
\hline
\end{tabular}

Table 6. Spherical roller bearing fatigue life test results.

\begin{tabular}{cccc}
\hline Spherical Roller Bearing & Time $\mathbf{h}$ & Rotating Speed rpm & Ratio $\%$ \\
\hline Untreated & 53.47 & $6.5 \times 10^{5}$ run out & 100.0 \\
UNSM-treated & 83.24 & $1 \times 10^{6}$ run out & 155.0 \\
\hline
\end{tabular}

\subsection{Validation in Fatigue Test of Bearing Ring}

In order to justify the effect of UNSM technology in real bearings, a small ring of taper roller bearing (30210A) was selected for comparison tests. At a maximum stress of $1.29 \mathrm{GPa}$, the untreated ring was failed at $8 \times 10^{5}$ cycles, while the UNSM-treated ring was runout after $10 \times 10^{6}$ cycles.

\subsection{Possibility to Eliminate Super Polishing Process of Ring and Roller}

The main purpose of super-polishing the raceways is to increase $\lambda$ factor under the lubrication regimes. This is defined as oil film thickness divided by equivalent surface roughness of both of the mating surfaces and to reduce the friction coefficient. The average surface roughness (Ra) of the normal thrust ring of $0.18 \mu \mathrm{m}$ reduced to $0.08 \mu \mathrm{m}$, where the surface structure was changed into a dimpled/textured structure, as shown Figure 4. The exact dimensions, such as the diameter and depth of the produced dimples can be found in the previous study [11]. The surface roughness of the untreated roller with a diameter of $43 \mathrm{~mm}$ was about $0.35 \mu \mathrm{m}$, which reduced to $0.21 \mu \mathrm{m}$ after UNSM technology. The dimpled surface that is shown in Figure 4B may be produced on the surface of the bearing raceway to reduce the friction coefficient and wear rate during the rolling and sliding in the interaction contact of the ball and the raceway. The deformation-induced transformation mechanism can explain the surface hardening through the compressive residual stress and increase in the dislocation density. The average friction coefficient at the variation with rotation speed and load can be reduced by $22 \sim 39 \%$ [14]. Hence, except for aircraft bearings, the super polishing of slim ring bearings for the surface roughness ( $\mathrm{Ra}$ ) of $0.06 \mu \mathrm{m}$ could be replaced by $0.08 \mu \mathrm{m}$ and micro dimples by UNSM technology.
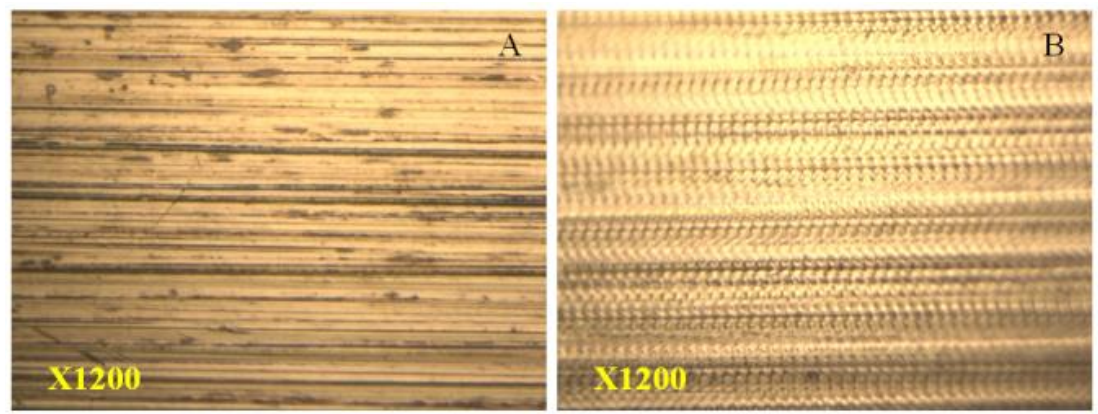

Figure 4. Polished (A) and UNSM-treated (B) roller surface of the taper roller bearings.

\section{Possibility of Downsizing of Slim Bearings}

The dynamic load rating of bearings is the main factor to select a proper specification of bearings and could be derived by ISO standard as Equations (1) and (2) [19] for ball and roller bearings, respectively. The $\mathrm{L}_{10}$ service life of bearings could also be derived by those equations. When it is supposed that the improved RCF has the same effect on the $\mathrm{L}_{10}$ condition, the increased basic dynamic load rating could be derived from Equations (5) and (6) [19] for the ball and roller bearings, respectively. 
A summary of RCF for the ball and roller test results that were obtained at a contact stress of $4.2 \mathrm{GPa}$ are listed in Tables 7 and 8.

Table 7. Summary of fatigue test results.

\begin{tabular}{cccc}
\hline Fatigue Test & Treatment & Fatigue, Cycles & Ratio, \% \\
\hline \multirow{2}{*}{ RCF (ball) } & Untreated & $4.641 \times 10^{6}$ & 100.0 \\
& UNSM-treated & $10.119 \times 10^{6}$ & 218.0 \\
\hline \multirow{2}{*}{ RCF (Roller) } & Untreated & $12.96 \times 10^{6}$ & 100.0 \\
& UNSM-treated & $40.88 \times 10^{6}$ & 315.0 \\
\hline \multirow{2}{*}{ Ball bearing fatigue test } & Untreated & $0.4395 \times 10^{6}$ & 100.0 \\
& UNSM-treated & $3.06 \times 10^{6}$ & 696.0 \\
\hline \multirow{2}{*}{ Roller bearing fatigue test } & Untreated & $6.454 \times 10^{5}$ & 100.0 \\
& UNSM-treated & $1 \times 10^{6}$ run out & 155.0 \\
\hline
\end{tabular}

Table 8. Basic dynamic load rating of the UNSM-treated specimens.

\begin{tabular}{ccc}
\hline Fatigue Test & Treatment & C-Basic Dynamic Load Rating of Bearings \\
\hline \multirow{2}{*}{ RCF (ball) } & Untreated & Equation $(1)$ \\
& UNSM-treated & $1.297 \times \mathrm{P}$ \\
\hline \multirow{2}{*}{ RCF (roller) } & Untreated & Equation $(2)$ \\
& UNSM-treated & $1.41 \times \mathrm{P}$ \\
\hline \multirow{2}{*}{ Ball bearing fatigue test } & Untreated & Equation $(1)$ \\
& UNSM-treated & $1.910 \times \mathrm{P}$ \\
\hline \multirow{2}{*}{ Roller bearing fatigue test } & Untreated & Equation $(2)$ \\
& UNSM-treated & $1.14 \times \mathrm{P}$ \\
\hline
\end{tabular}

For ball bearings:

$$
\mathrm{L}_{10}=\left(\frac{\mathrm{C}}{\mathrm{P}}\right)^{3}
$$

For roller bearings:

$$
\mathrm{L}_{10}=\left(\frac{\mathrm{C}}{\mathrm{P}}\right)^{\frac{10}{3}}
$$

where: $\mathrm{L}_{10}$ is the fatigue life that $90 \%$ of a sufficiently large group of apparently identical bearings can be expected to reach or exceed; $P$ is the equivalent dynamic bearing load; $C$ is the basic dynamic load rating of the ball bearings that were obtained from Equation (1) as follows:

$$
\mathrm{L}_{10}^{\frac{1}{3}}=\frac{\mathrm{C}}{\mathrm{P}} \rightarrow \mathrm{C}=\mathrm{L}_{10}^{\frac{1}{3}} \cdot \mathrm{P}
$$

It is possible to design the improved range of dynamic load. The minimum value for ring, RCF (ball) could be as follows:

$$
\mathrm{C}_{\mathrm{UNSM}}=\mathrm{L}_{10}^{\frac{1}{3}} \cdot \mathrm{P}=1.2966 \cdot \mathrm{P}
$$

It is possible to design the improved range of dynamic. The maximum value for the ball bearing fatigue test could be as follows:

$$
\mathrm{C}_{\mathrm{UNSM}}=\mathrm{L}_{10}^{\frac{1}{3}} \cdot \mathrm{P}=6.96 \cdot \mathrm{P}
$$

The UNSM-treated ball bearings $C_{\text {UNSM }}$ could be derived as Equation (3):

$$
1.29 \mathrm{C}<\mathrm{C}_{\mathrm{UNSM}}<1.9
$$


C was obtained from Equation (2) as follows:

$$
\mathrm{L}_{10}^{\frac{3}{10}}=\frac{\mathrm{C}}{\mathrm{P}} \rightarrow \mathrm{C}=\mathrm{L}_{10}^{\frac{3}{10}} \cdot \mathrm{P}
$$

It is possible to design the improved range of dynamic. The maximum value for the RCF (roller) fatigue test could be as follows:

$$
\mathrm{C}_{\mathrm{UNSM}}=\mathrm{L}_{10}^{\frac{3}{10}} \cdot \mathrm{P}=3.15^{\frac{3}{10}} \cdot \mathrm{P}=1.41 \cdot \mathrm{P}
$$

It is possible to design the improved range of dynamic. The maximum value for the roller fatigue test could be as follows:

$$
\mathrm{C}_{\mathrm{UNSM}}=\mathrm{L}_{10}^{\frac{3}{10}} \cdot \mathrm{P}=1.55^{\frac{3}{10}} \cdot \mathrm{P}=1.14 \cdot \mathrm{P}
$$

The UNSM-treated roller bearings $\mathrm{C}_{\mathrm{UNSM}}$ could be derived as Equation (4):

$$
1.14 \mathrm{C}<\mathrm{C}_{\mathrm{UNSM}}<1.41
$$

\subsection{Downsizing of Slim Ball Bearing}

A typical slim ball bearing with an outer diameter of $177.8 \mathrm{~mm}$ and an inner diameter of $165.0 \mathrm{~mm}$ and a width of $6.35 \mathrm{~mm}$ was used. Table 9 shows the possibility of reducing the size and weight of a bearing by UNSM technology.

Table 9. The possibility of reducing the size and weight of a slim ball bearing by UNSM technology at two different dynamic load ratings UNSM A and UNSM B.

\begin{tabular}{ccccc}
\hline Dimensions & Meanings & Untreated & UNSM A & UNSM B \\
\hline $\mathrm{d}, \mathrm{mm}$ & bearing inner diameter & 165.0 & 165.0 & 160 \\
\hline $\mathrm{D}, \mathrm{mm}$ & bearing outer diameter & 177.8 & 175.3 & 172 \\
\hline $\mathrm{B}, \mathrm{mm}$ & bearing width & 6.35 & 6 & 5 \\
\hline \multirow{2}{*}{$\mathrm{L}, \mathrm{N}$} & dynamic load & $\mathrm{C}$ & $\mathrm{C}_{1.297-\mathrm{UNSM}}$ & $\mathrm{C}_{1.14-\mathrm{UNSM}}$ \\
\cline { 3 - 5 } & \multirow{2}{*}{ ball diameter } & - & 7249.2 & $10,675.3$ \\
\cline { 3 - 5 } $\mathrm{d}_{\text {ball }, \mathrm{mm}}$ & & 5.9 & 3 & 3 \\
\hline $\mathrm{W}, \mathrm{kg}$ & bearing weight & 0.119 & 6.088 & 66 \\
\hline
\end{tabular}

The basic dynamic load rating Equation (5) [19] for radial ball bearings.

$$
\mathrm{C}=\mathrm{f}_{\mathrm{cm}}(\mathrm{i} \cos \alpha)^{0.7} \mathrm{Z}^{\frac{2}{3}} \mathrm{D}^{1.8}
$$

UNSM-A $C_{\text {UNSM }}$

$$
\begin{gathered}
\gamma=\frac{\mathrm{D} \cos \alpha}{\mathrm{d}_{\mathrm{m}}}=\frac{3 \cos 30}{170}=0.0152 \\
\mathrm{C}=\mathrm{f}_{\mathrm{cm}}(\mathrm{i} \cos \alpha)^{0.7} \mathrm{Z}^{\frac{2}{3}} \mathrm{D}^{1.8}=5589.2 \mathrm{~N} \\
\mathrm{C}_{\mathrm{UNSM}}=\mathrm{C} \cdot 1.297=7249.2 \mathrm{~N}
\end{gathered}
$$

UNSM-B C $\mathrm{UNSM}_{\mathrm{N}}$

$$
\begin{gathered}
\gamma=\frac{\mathrm{D} \cos \alpha}{\mathrm{d}_{\mathrm{m}}}=\frac{3 \cos 30}{166}=0.0156 \\
\mathrm{C}=\mathrm{f}_{\mathrm{cm}}(\mathrm{i} \cos \alpha)^{0.7} \mathrm{Z}^{\frac{2}{3}} \mathrm{D}^{1.8}=5589.2 \mathrm{~N}
\end{gathered}
$$




$$
\mathrm{C}_{\mathrm{UNSM}}=\mathrm{C} \cdot 1.910=10,675.3 \mathrm{~N}
$$

where: $f_{\mathrm{cm}}$ is the factor for calculating C; $\mathrm{i}$ is the number of rows of balls; $\alpha$ is the contact angle, degree; $\mathrm{z}$ is the number of rolling elements per row; $\mathrm{D}$ is the diameter of the balls.

In the case where the inner diameter is kept the same, the ball size could be reduced from 3.9 to $3 \mathrm{~mm}$ and the on and width could be reduced to 6.35 and $6 \mathrm{~mm}$, while the dynamic load rating with UNSM technology maintains the same level. The weight could be reduced from 0.119 to $0.088 \mathrm{~kg}$. In the case of the inner diameter, it could also be changed from 165 to $160 \mathrm{~mm}$, and the ball size could be reduced from 3.9 to $3 \mathrm{~mm}$ also. So, the outer diameter and width could be reduced to 6.35 and $5 \mathrm{~mm}$, while the dynamic load rating with UNSM technology could be maintained at the same level. The weight could be reduced from 0.119 to $0.085 \mathrm{~kg}$. The maximum equivalent stress that is induced by normal force at the outer ring are analyzed by finite element analysis (FEA) and are compared, as shown in Figure 5 and Table 10. When considering the increased fatigue strength by $28 \%$ after UNSM technology on the ring, the fatigue life of the reduced size of the bearings needs to be longer than the untreated bearings.
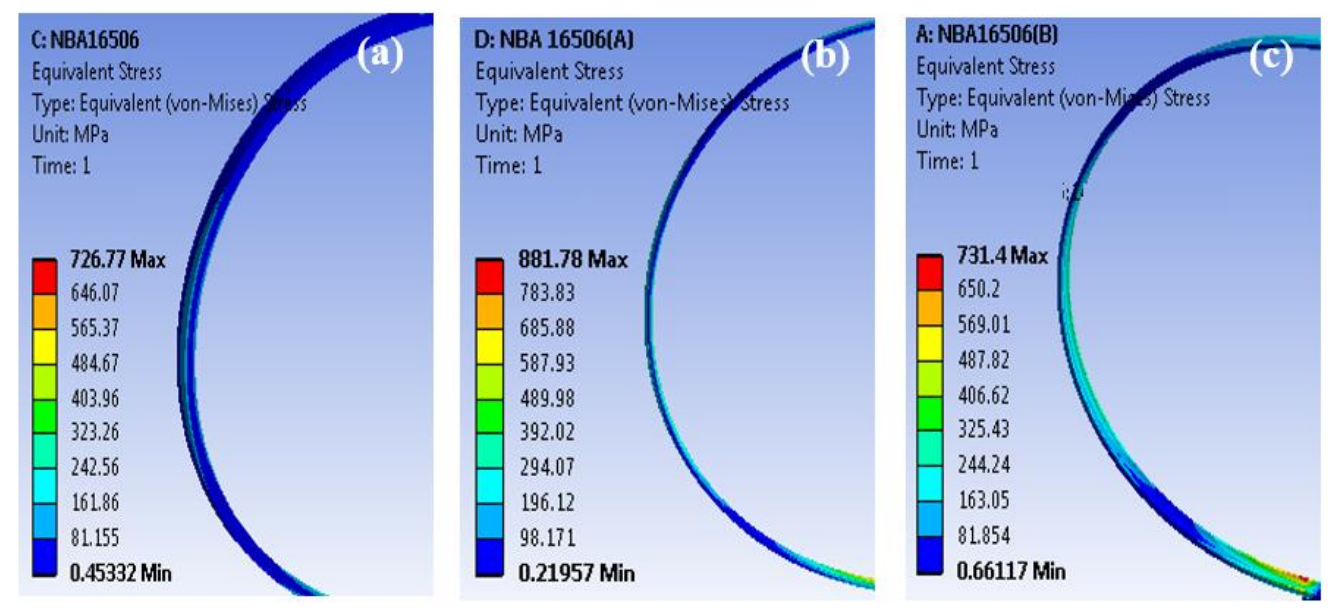

Figure 5. ANSYS equivalent stress result of angular contact ball bearings of outer ring: (a) untreated ring, (b) UNSM-A ring, (c) UNSM-B ring.

Table 10. Comparison in stress results of angular contact ball bearings for the untreated and two different dynamic load ratings UNSM A and UNSM B.

\begin{tabular}{cccc}
\hline Bearings & Load N & Stress MPa & $\begin{array}{c}\text { UNSM 28\% (Increase in Fatigue Strength } \\
\text { by UNSM Technology by 28\%) }\end{array}$ \\
\hline Untreated & 100 & 726.8 & - \\
UNSM A & 100 & 881.9 & 1128.8 \\
UNSM B & 100 & 731.3 & 936.0 \\
\hline
\end{tabular}

\subsection{Downsizing of Slim Roller Bearing}

The dimensions of a typical slim roller bearing with an outer diameter of $150 \mathrm{~mm}$, an inner diameter of $100 \mathrm{~mm}$, and a width of $24 \mathrm{~mm}$ are listed in Table 11, which shows the possibility of reducing the size and weight of a bearing by UNSM technology.

The basic dynamic load rating Equation (6) [19] for radial roller bearings:

$$
\mathrm{C}=\mathrm{f}_{\mathrm{cm}}(\mathrm{iL} \cos \alpha)^{\frac{7}{9}} \mathrm{Z}^{\frac{3}{4}} \mathrm{D}^{\frac{29}{27}}
$$

UNSM-A C $C_{\text {UNSM }}$

$$
\gamma=\frac{\mathrm{D} \cos \alpha}{\mathrm{d}_{\mathrm{m}}}=\frac{11 \cos 0}{125.5}=0.087
$$




$$
\begin{gathered}
\mathrm{C}=\mathrm{f}_{\mathrm{cm}}(\mathrm{iL \operatorname {cos } \alpha})^{\frac{7}{9}} \mathrm{Z}^{\frac{3}{4}} \mathrm{D}^{\frac{29}{27}}=4524.8 \mathrm{~N} \\
\mathrm{C}_{\mathrm{UNSM}}=1.41 \mathrm{C}=6379.9 \mathrm{~N}
\end{gathered}
$$

UNSM-B C $\mathrm{UNSM}$

$$
\begin{gathered}
\gamma=\frac{\mathrm{D} \cos \alpha}{\mathrm{d}_{\mathrm{m}}}=\frac{11 \cos 0}{120}=0.091 \\
\mathrm{C}=\mathrm{f}_{\mathrm{cm}}(\mathrm{iL \operatorname {cos } \alpha})^{\frac{7}{9}} \mathrm{Z}^{\frac{3}{4}} \mathrm{D}^{\frac{29}{27}}=4524.8 \mathrm{~N} \\
\mathrm{C}_{\mathrm{UNSM}}=1.41 \mathrm{C}=5158.3 \mathrm{~N}
\end{gathered}
$$

Table 11. The possibility of reducing the size and weight of slim roller bearings by UNSM technology at two different dynamic load ratings UNSM A and UNSM B.

\begin{tabular}{ccccc}
\hline Dimensions & Meanings & Untreated & UNSM A & UNSM B \\
\hline $\mathrm{d}, \mathrm{mm}$ & bearing inner diameter & 100 & 100 & 95 \\
\hline $\mathrm{D}, \mathrm{mm}$ & bearing outer diameter & 150 & 145 & 140 \\
\hline $\mathrm{B}, \mathrm{mm}$ & bearing width & 24 & 20 & 20 \\
\hline \multirow{2}{*}{ Load, $\mathrm{N}$} & dynamic load & $\mathrm{C}$ & $\mathrm{C}_{1.41-\text { UNSM }}$ & $\mathrm{C}_{1.14-\mathrm{UNSM}}$ \\
& & - & 6379.9 & 5158.3 \\
\hline \multirow{2}{*}{$\mathrm{d}_{\text {ball }}, \mathrm{mm}$} & \multirow{3}{*}{ ball diameter } & 12 & 11 & 11 \\
& & 10 & 9 & 9 \\
$\mathrm{~W}, \mathrm{~kg}$ & bearing weight & 12 & 13 & 13 \\
\hline
\end{tabular}

The maximum equivalent stress induced by normal force at the outer ring are analyzed by FEA (ANSYS Inc., Canonsburg, PA, USA) and are compared, as shown in Figure 6. Considering the increased fatigue strength by $28 \%$ after UNSM treatment on the ring is shown in Table 12.
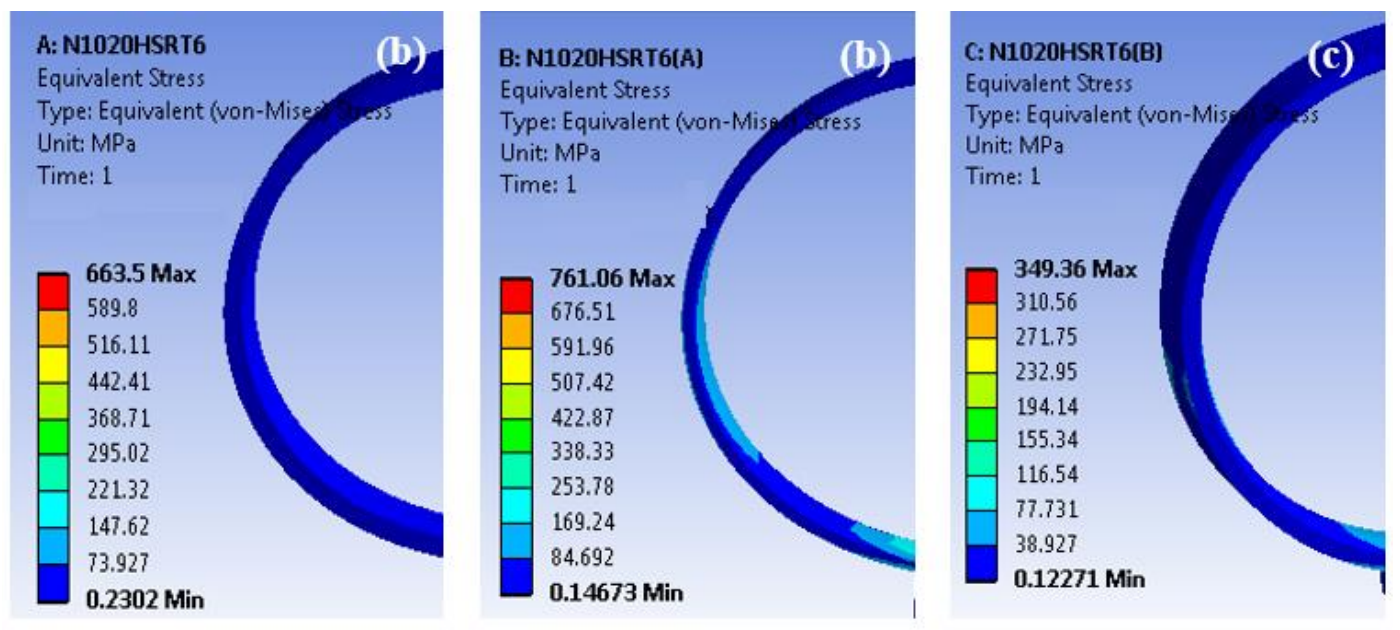

Figure 6. ANSYS equivalent stress result of roller bearings of the outer ring: (a) untreated ring, (b) UNSM-A ring, (c) UNSM-B ring. 
Table 12. Comparison in stress results of roller bearings for the untreated and two different dynamic load ratings UNSM A and UNSM B.

\begin{tabular}{cccc}
\hline Bearings & Load N & Stress MPa & $\begin{array}{c}\text { UNSM 28\% (Increase in Fatigue Strength } \\
\text { by UNSM Technology by 28\%) }\end{array}$ \\
\hline Untreated & 500 & 663.5 & - \\
UNSM A & 500 & 761.0 & 974.1 \\
UNSM B & 500 & 349.4 & 447.2 \\
\hline
\end{tabular}

In cases where the inner diameter is kept the same, the roller size could be reduced from $12 \times 10$ to $11 \times 9 \mathrm{~mm}^{2}$ and the outer diameter and width could be reduced to 24 and $20 \mathrm{~mm}$, while the dynamic load rating with UNSM technology is maintained at the same level. The weight could be reduced from 1.05 to $0.74 \mathrm{~kg}$. In cases when the inner diameter could be reduced from 100 to $95 \mathrm{~mm}$, the roller size could be reduced from $12 \times 10$ to $10 \times 9 \mathrm{~mm}^{2}$ as well. So, the outer diameter and width could be reduced to 24 and $20 \mathrm{~mm}^{2}$, while the dynamic load rating with UNSM technology is maintained at the same level. The weight could be reduced from 1.05 to $0.90 \mathrm{~kg}$. The maximum equivalent stress on both rings of three bearings under dynamic load rating and static load rating are compared in Table 12. These results can validate that the reduced size of the bearings will have a longer service life in RCF than those of the original bearings, respectively. The possibility of reducing the size and weight of slim bearings is also summarized in Tables 9 and 11.

\section{Conclusions}

In this study, the fatigue results and improvement percentages of the untreated and UNSM-treated specimens were obtained within the performed experimental metrics. This study validated that the RCF strength could be improved by about 118 and $28 \%$, respectively, while cycles to failure on RCF of thrust ball and spherical roller bearings could be increased by about $596 \%$ and $55 \%$, respectively. Also, the friction coefficient of thrust ball bearings could be reduced by about $55 \sim 118 \%$ by UNSM treatment depending on treatment parameters. The analysis showed that the weight of slim ball and roller bearings could be reduced by about $3.40 \sim 21.25 \%$ and $14.3 \sim 26.05 \%$, respectively. Hence, a huge amount of materials and energy can be saved by reducing the weight and size of bearings by adapting a UNSM technology.

Author Contributions: “Conceptualization, Y.-S.P. and A.A.; Methodology, Y.-S.P., S.D. and A.A.; Software, D.S.; Validation, Y.-S.P., S.D. and A.A.; Analysis, A.A. and S.D.; Investigation, A.A.; Writing-Original Draft Preparation, Y.-S.P., S.D. and A.A.; Writing-Review \& Editing, A.A.; Funding Acquisition, A.A. and Y.-S.P."

Funding: This research was funded by the Start-Up Research Project through the Ministry of Science, ICT, and Future Planning of Korea (NRF-2017R1C1B5017434). This study was also partially supported by the Korea Technology and Information Promotion Agency (TIPA) for Small and Medium Enterprises. Project (No. S2544322).

Conflicts of Interest: The authors declare no conflict of interest.

\section{References}

1. Paulson, N.R.; Golmohammadi, Z.; Walvekar, A.A.; Sadeghi, F.; Mistry, K. Rolling contact fatigue in refurbished case carburized bearing. Tribol. Int. 2017, 115, 348-364. [CrossRef]

2. Recerz, P.; Olver, A.; Kadiric, A. Propagation of surface initiated rolling contact fatigue cracks in bearing steel. Int. J. Fatigue 2017, 97, 29-38. [CrossRef]

3. Sharma, V.K. Rolling contact fatigue study of austempered ductile iron. J. Heat. Treat. 1984, 3, 326-334. [CrossRef]

4. Smelova, V.; Schwendt, A.; Wang, L.; Holweger, W.; Mayer, J. Electron microscopy investigations of microstructural alterations due to classical rolling contact fatigue (RCF) in martensitic AISI 52100 bearing steel. Int. J. Fatigue 2017, 98, 142-154. [CrossRef] 
5. Osterlund, R.; Vingsbo, O. Phase changes in fatigued ball-bearings. Metall. Trans. A 1980, 11, $701-707$. [CrossRef]

6. Swahn, H.; Becker, P.C.; Vingsbo, O. Martensite decay during rolling-contact fatigue in ball-bearings. Metall. Trans. A 1976, 7, 1099-1110. [CrossRef]

7. Pramanik, A.; Dixit, A.R.; Chattopadhyaya, S.; Uddin, M.S.; Dong, Y.; Basak, A.K.; Littlefair, G. Fatigue life of machined components. Adv. Manuf. 2017, 5, 59-76. [CrossRef]

8. Vetters, H.; Dong, J.; Bomas, H.; Hoffmann, F.; Zoch, H.W. Microstructure and fatigue strength of the roller-bearing steel 100Cr6 (SAE52100) after two-step bainitisation and combined bainitic-martensitic heat treatment. Int. J. Mater. Res. 2006, 97, 1432-1440. [CrossRef]

9. Kerscher, E.; Lang, K.H.; Vohringer, O.; Lohe, D. Increasing the fatigue limit of a bearing steel by dynamic strain ageing. Int. J. Fatigue 2008, 30, 1838-1842. [CrossRef]

10. Kerscher, E.; Lang, K.H. Increasing the fatigue limit of a high-strength bearing steel by a deep cryogenic treatment. J. Phys. Conf. Ser. 2010, 240, 012059. [CrossRef]

11. Amanov, A.; Cho, I.S.; Pyun, Y.S.; Lee, C.S.; Park, I.G. Micro-dimpled surface by ultrasonic nanocrystal surface modification and its tribological effects. Wear 2012, 286-287, 136-144. [CrossRef]

12. Pyun, Y.S.; Kim, J.H.; Kayumov, R.; He, Y.; Shin, K.S. Restoration of rolling-contact-fatigued surfaces via nanoskin technology. J. Nanosci. Nanotechnol. 2013, 13, 6371-6375. [CrossRef] [PubMed]

13. Cordero, Z.C.; Knight, B.E.; Schuh, C.A. Six decades of the Hall-Petch effect-A survey of grain-size strengthening studies on pure metals. Int. Mater. Rev. 2016, 61, 495-512. [CrossRef]

14. Amanov, A.; Sasaki, S.; Pyun, Y.S. Frictional behavior of duplex nano-corrugated and nanostructured Cu alloy produced by UNSM. Procedia Eng. 2013, 68, 491-496. [CrossRef]

15. Allison, B.; Subnash, G.; Arakere, N.; Haluck, D.A.; Chin, H. Influence of initial residual stress on material properties of bearing steel during rolling contact fatigue. Tribol. Trans. 2014, 57, 535-545. [CrossRef]

16. Lammi, C.J.; Lados, D.A. Effect of processing residual stress on fatigue crack growth behavior of structural materials: Experimental approaches and microstructural mechanisms. Metall. Mater. Trans. A 2012, 43, 87-107. [CrossRef]

17. Amanov, A.; Cho, I.S.; Kim, D.E.; Pyun, Y.S. Fretting wear and friction reduction of CP titanium and Ti-6Al-4V alloy by ultrasonic nanocrystalline surface modification. Surf. Coat. Technol. 2012, 207, 135-142. [CrossRef]

18. Chokshi, A.H.; Rosen, A.; Karch, J.; Gleiter, H. On the validity of the Hall-Petch relationship in nanocrystalline materials. Scr. Metall. 1989, 23, 1679-1683. [CrossRef]

19. Harris, T.A.; Kotzalas, M.N. Essential Concepts of Bearing Technology, 5th ed.; Taylor \& Francis, CRC: New York, NY, USA, 2007. 